\title{
Copper and zinc speciation in soils from paddy cultivation areas in Kelantan, Malaysia.
}

\begin{abstract}
The purpose of this study was to investigate the present concentration of copper $(\mathrm{Cu})$ and zinc $(\mathrm{Zn})$, and factors controlling the bioavailability of metals in paddy cultivation soils collected from Kelantan. $\mathrm{Cu}$ and $\mathrm{Zn}$ levels in soil samples were extracted by using the sequential extraction procedures, which are namely easily or freely, leachable and exchangeable (EFLE), acid-reducible, oxidisable-organic and resistant fractions. The highest concentration of $\mathrm{Cu}$ was found in the oxidisable-organic fraction $(19.77 \pm 1.89 \mu \mathrm{g} / \mathrm{g})$ for March, while the resistant fraction $(18.29 \pm 0.87 \mu \mathrm{g} / \mathrm{g})$ was the highest in April. In contrast, $\mathrm{Zn}$ concentration was the highest in the resistant fraction for both months. Statistically, $\mathrm{Cu}$ and $\mathrm{Zn}$ results showed a non-significant difference among these two months in the fraction of paddy soil studied. These results indicate a low bioavailability of $\mathrm{Cu}$ and $\mathrm{Zn}$ in the paddy cultivation soils. Therefore, the anthropogenic-based $\mathrm{Cu}$ and $\mathrm{Zn}$ in the paddy cultivation areas of Kelantan are expected to originate from applications of chemical fertilizers and pesticide, not from the lithogenic sources.
\end{abstract}

Keyword: $\mathrm{Cu}$ and Zn; Bioavailability; Soils; Paddy cultivation; Anthropogenic. 